\title{
A comprehensive evaluation method for the security situation of distributed power supply in distribution network
}

\author{
Bo $\mathrm{Wu}^{1, \mathrm{a}^{*}}$ \\ ${ }^{1}$ Institute of Advanced Technology, Nanjing University of Posts and Telecommunications,Nanjing,Jiangsu, China
}

\begin{abstract}
In order to study the influence of distributed power access on the security state of distribution network, a comprehensive evaluation method for the security state of distribution network including distributed power access was proposed.Based on the output model and load model of photovoltaic power supply, the security situation assessment index system of distributed power supply access distribution network is established. Then combined with fuzzy analytic hierarchy process and entropy weight method, the composite weight of each index is obtained, and the combined weight is optimized based on chi-square distance. Finally, the evaluation method based on ER algorithm (Evidential Reasoning) is proposed. Simulation results verify the effectiveness and accuracy of the proposed method.
\end{abstract}

\section{Introduction}

After more and more distributed power supply (DG) is connected to the distribution network, it will have an impact on the operation state of the distribution network, and security is an important aspect of it. Therefore, it is necessary to effectively evaluate and analyze it, which is conducive to the promotion and development of distributed power supply [1,2].

Key indexes such as voltage change rate and average voltage fluctuation are analyzed in literature [3-4], as well as the influence degree of different distributed power grid connection on voltage. [5-8] for distributed power distribution network access, the size of the trend and direction, the great changes will make the distribution network voltage changes, the grid security divided into different levels, from risk index, the static safety index such as index evaluation column grid solution, the more voltage limit, voltage security situation, but the assessment method are clear enough. Literature [8] adopts the subjective and objective weighting method to conduct a comprehensive assessment of power quality, but it is only applied to the comprehensive assessment of power quality and cannot withdraw the security of distribution network. Literature [9] puts forward the comprehensive evaluation of power quality only. Security is reflected in the power supply capacity and power supply quality of the power system, which must be considered in the actual operation of the power system. It can be judged by the data of the power system under specific conditions.

On the basis of the above research, this paper proposes the combinatorial weights based on chi-square distance optimization and the evaluation method of ER algorithm. First established the distributed power distribution network access security situation assessment index system, in order to avoid a single method to determine the weight when there is one-sidedness, combined with the fuzzy analytic hierarchy process (AHP) and entropy weight method to get the composite weight of each index, in order to make the weight allocation and closer to the actual results, and based on chi-square distance to optimize the combination of empowerment and finally put forward the evaluation method based on ER algorithm, the security level of grading. A simulation example of IEEE33 node is used to verify the method.

\section{Distributed power output characteristics}

\subsection{Photovoltaic generator model}

According to the statistical rule, in a relatively short period of time, the radiation intensity of sunlight meets the Beta distribution, and its probability density function is $[10]$ :

$$
f(i)=\frac{\Gamma(\alpha+\beta)}{\Gamma(\alpha) \Gamma(\beta)}\left(\frac{i}{i_{\max }}\right)^{\alpha-1}\left(1-\frac{i}{i_{\max }}\right)^{\beta-1}
$$

Where, $i$ and $i_{\max }$ are the radiation intensity and maximum radiation intensity of sunlight in a certain period of time, and $\alpha$ and $\beta$ are the shape parameters of Beta distribution.

For the solar photovoltaic power supply, the photoelectric conversion efficiency and area distribution are $w$ and $s$, and the output power $P_{p v}$ is:

$$
P_{p v}=\omega i S
$$

\footnotetext{
a, ${ }^{*}$ Corresponding author:945784220@qq.com
} 


\subsection{Load random model}

The load of the system is time-varying, and the fluctuation of the load will increase the risk to the safe and stable operation of the distribution network. For the continuous type of load, normal distribution is usually used to represent its fluctuation. Assuming that the expected value and variance distribution of load active power and reactive power are $\mu_{p} 、 \sigma_{p}{ }^{2}$ and $\mu_{q} 、 \sigma_{q}{ }^{2}$, the probability density function distribution of active power and reactive power is:

$$
\begin{aligned}
& f(P)=\frac{1}{\sqrt{2 \pi \sigma_{p}}} \exp \left(-\frac{\left(P-\mu_{p}\right)^{2}}{2 \sigma_{p}^{2}}\right) \\
& f(\mathrm{q})=\frac{1}{\sqrt{2 \pi \sigma_{q}}} \exp \left(-\frac{\left(P-\mu_{q}\right)^{2}}{2 \sigma_{q}^{2}}\right)
\end{aligned}
$$

\section{Security situation assessment model of distributed power supply access distribution network}

\subsection{Security Situation index of distributed power Supply access distribution Network security Situation Assessment Model}

Traditional distribution network security evaluation mainly include network overload and voltage is limited, but the access of distributed power supply makes the traditional distribution network into a middle and small power supply and load of power grid, the access of distributed power supply makes containing qualitative changes have taken place in the safety of the distributed power distribution network, to distribution network node voltage, current, network loss, the steady-state many effects such as [11-13].

Based on the existing evaluation indexes, the paper establishes the distribution network security indexes of distributed power access from the perspectives of power supply capacity and quality, so as to investigate the security of distribution network in the case of distributed power access.

Therefore, the security evaluation indexes constructed in this paper are shown in Table1.
Tab1 Security index system of distribution network with

\begin{tabular}{|c|c|c|}
\hline First class index & $\begin{array}{l}\text { Second } \\
\text { class } \\
\text { index }\end{array}$ & Explain \\
\hline \multirow{4}{*}{$\begin{array}{l}\text { capacity of } \\
\text { electric power } \\
\text { supply: } U_{1}\end{array}$} & $\begin{array}{l}\text { On-positi } \\
\text { on: } U_{11}\end{array}$ & $\begin{array}{c}\text { Distributed power access } \\
\text { location }\end{array}$ \\
\hline & $\begin{array}{l}\text { Access to } \\
\text { the } \\
\text { capacity } \\
U_{12}\end{array}$ & $\begin{array}{l}\text { The ratio of the total access } \\
\text { power } P \text { of a distributed } \\
\text { power supply } P_{a c} \text { to its } \\
\text { actual capacity }\end{array}$ \\
\hline & $\begin{array}{l}\text { Slow } \\
\text { release of } \\
\text { active } \\
\text { work } U_{13}\end{array}$ & $\begin{array}{l}\text { The difference ratio } P_{n a} \\
\text { between the active power } \\
P_{n a} \text { of a line without access } \\
\text { to the distributed power } \\
\text { supply and the active power } \\
P_{a} \text { after access is used to } \\
\text { measure the degree of slow } \\
\text { release of the active power } \\
\text { transferred to the line after } \\
\text { access to the distributed } \\
\text { power supply }\end{array}$ \\
\hline & $\begin{array}{l}\text { Voltage } \\
\text { deviation } \\
\text { rate } U_{14}\end{array}$ & $\begin{array}{l}\text { The ratio of the nodes } \\
\text { operating within the } \\
\text { allowable voltage deviation } \\
\text { range to the total nodes. }\end{array}$ \\
\hline \multirow{3}{*}{$\begin{array}{l}\text { power supply qua } \\
\text { lity } U_{2}\end{array}$} & $\begin{array}{l}\text { Voltage } \\
\text { fluctuatio } \\
\mathrm{n} U_{21}\end{array}$ & $\begin{array}{l}U_{21}=\frac{u_{a}-u_{n a}}{u_{a}} \text {, Where, } u_{a} \\
\text { is the node voltage after the } \\
\text { distributed power supply is } \\
\text { connected, and } u_{n a} \text { is the } \\
\text { voltage before the distributed } \\
\text { power supply is connected, } \\
\text { reflecting the supporting role } \\
\text { of the distributed power } \\
\text { supply to the node voltage }\end{array}$ \\
\hline & $\begin{array}{c}\text { Network } \\
\text { loss rate } \\
U_{22}\end{array}$ & $\begin{array}{l}\text { The ratio of active power } \\
\text { loss to total power supply } \\
\text { after distributed power } \\
\text { supply is connected, the loss } \\
\text { rate of HV and LV power } \\
\text { grid should be controlled } \\
\text { below } 8 \% \text { and } 12 \% \\
\text { respectively }\end{array}$ \\
\hline & $\begin{array}{c}\text { Tidal } \\
\text { equalizati } \\
\text { on } \\
U_{23}\end{array}$ & $\begin{array}{c}\text { Sys_E }=\sum_{i}^{n}\left(\frac{n H_{i}-\sum_{k=1}^{n} H_{k}}{n}\right. \\
\text {, Where, } H_{i} \text { is the ratio } \\
\text { between the actual power and } \\
\text { the actual ultimate power of } \\
\text { a certain line, reflecting } \\
\text { whether the power flow of } \\
\text { the grid is distributed } \\
\text { evenly. When the load is } \\
\text { constant, the smaller the } \\
\text { power balance is, the higher } \\
\text { the safety of distributed } \\
\text { power is after it is connected } \\
\text { to the distribution network. }\end{array}$ \\
\hline
\end{tabular}
distributed power 


\subsection{The evaluation grade corresponding to the evaluation index}

The security situation evaluation of distributed power supply access involves many indexes, and how to describe the indexes effectively determines the accuracy of the security evaluation of distributed power supply access distribution network.

Using the utility theory, the evaluation indexes are processed, among which $\mathrm{n}$ indexes are $U_{11} 、 U_{12} \cdots U_{2 n}$ and the membership matrix corresponding to each index is $\varphi_{i}(x)\left(i={ }_{11},{ }_{12} \cdots_{2 n}\right)$, which can form the following matter-element matrix:

$$
V_{j}=\left(\begin{array}{cc}
U_{11} & \varphi_{11}(x) \\
U_{12} & \varphi_{12}(x) \\
\vdots & \vdots \\
\vdots & \vdots \\
U_{2 n} & \varphi_{2 n}(x)
\end{array}\right)
$$

$V_{j}$ represents the safety of the distribution network at level $j$, (range_low $w_{1}$,range_up $_{1}$ ) represents the matter-element matrix corresponding to the evaluation interval with good safety, (range_low , range_up $_{2}$ ) represents the matter-element matrix corresponding to the evaluation interval with good safety, and so on, and the evaluation interval with five levels of good, good, general, poor, and very poor are determined respectively.

Based on the matter-element matrix and combined with the utility theory, the confidence distribution $R$ of the evaluation index of item $i$ was determined:

$$
R=\left\{\left(V_{j}, r_{i j}\right), j=1, \cdots, N\right\}
$$

Where, $r_{i j}$ represents the confidence of the value of the evaluation index to grade $V_{j}, V_{j}$ represents the evaluation grade for the safety evaluation of distribution network, and $N$ represents the series of the evaluation grade.

\subsection{Security evaluation based on ER algorithm}

The security situation evaluation of distributed power supply access involves many indexes, how to describe the indexes effectively, and the volatility and randomness of distributed power supply are difficult to be expressed quantitatively. ER algorithm by reasonable distribution of the weight of evidence and the membership grade, the features of the indicators have adapted in the decision making, thus ensuring high conflict evidence directly the accuracy of the fusion, avoid counterintuitive problem, using multiple indicators to evaluate the membership grade of the comprehensive judgement, the multi-level complex problems with good effect, can be distributed power distribution network access security comprehensive and reasonable evaluation result.

\subsubsection{Index set}

The set of security indicators determined by the security situation assessment of distributed power supply access to the distribution network adopts the indicators in Table 1 in section 3.1 , denoted as:

$$
U=\left\{U_{1} ; U_{2}\right\}=\left\{U_{11}, U_{12} 、 U_{13}, U_{14} ; U_{21}, U_{22} 、 U_{23}\right\}
$$

\subsubsection{Determination of weight coefficient}

(1) Subjective weighting method.

The weights of each index are determined according to the fuzzy AHP. The steps are as follows:

Step 1: The fuzzy ANALYTIC hierarchy process can take the form of multiple experts' ratings, and the ratings are given in the form of triangular fuzzy numbers. The ratings are given in the form of triangular fuzzy numbers with $m^{\prime}$ as the median value, and $l=m^{\prime}=u$ is then converted into the traditional analytic hierarchy process.

Step 2: Multiple experts scoring, the scoring matrix must be processed, so as to reduce the influence of experts' personal preference and make the multiple scoring matrices form a comprehensive fuzzy triangular judgment matrix.

The relative weight vector of the triangular fuzzy number can be calculated by the following formula:

$$
w_{c i}=\left(\frac{\sum_{j=1}^{n} a_{l i j}}{\sum_{i=1}^{n} \sum_{j=1}^{n} a_{u i j}}, \frac{\sum_{j=1}^{n} a_{m^{\prime} i j}}{\sum_{i=1}^{n} \sum_{j=1}^{n} a_{m^{\prime} i j}}, \frac{\sum_{j=1}^{n} a_{u i j}}{\sum_{i=1}^{n} \sum_{j=1}^{n} a_{l i j}}\right)
$$

Where $\frac{\sum_{j=1}^{n} a_{l i j}}{\sum_{i=1}^{n} \sum_{j=1}^{n} a_{u i j}}, \frac{\sum_{j=1}^{n} a_{m^{\prime} i j}}{\sum_{i=1}^{n} \sum_{j=1}^{n} a_{m^{\prime} i j}}, \frac{\sum_{j=1}^{n} a_{u i j}}{\sum_{i=1}^{n} \sum_{j=1}^{n} a_{l i j}}$ is the comprehensive fuzzy value of the evaluation index.

$a_{l i j}$ represents the triangular fuzzy number of the $i j$ bit, $a_{m^{\prime} i j}$ represents the triangular fuzzy number of the $i j$ bit, and $a_{u i j}$ represents the triangular fuzzy number of the ij bit.

Then, the fuzzy principle of "the probability that one fuzzy value is greater than other fuzzy values" is used to de-blur, and the weight is obtained:

$$
d\left(u_{1 i}\right)=\min V\left(u_{i}>u_{j}\right), j \neq i, j=1 \cdots n
$$

Where $u_{i}\left(l_{i}, m_{i}^{\prime}, u_{i}\right)$ and $u_{j}\left(l_{j}, m_{j}^{\prime}, u_{j}\right)$;

$$
V\left(u_{i}>u_{j}\right)=\left\{\begin{array}{cc}
1 & m^{\prime} i \geq m^{\prime} j \\
\frac{l_{i}-u_{i}}{\left(m_{i}^{\prime}-u_{i}\right)-\left(m_{j}^{\prime}-u_{j}\right)} & m^{\prime} i \leq m^{\prime} j, u i \geq \operatorname{lj}(10) \\
0 & \text { other }
\end{array}\right.
$$

Finally, the above weight $d\left(u_{1 i}\right)$ is standardized to obtain the weight $w\left(u_{1 i}\right)$ of the second level index. By using the same method, the index of the upper level is obtained, and then the subjective comprehensive weight set of each evaluation index is obtained:

$$
w_{1 i}=w\left(u_{i}\right) * w\left(u_{1 i}, u_{2 i}\right)=\left(w_{11}, w_{12}, \cdots, w_{1 n}\right)
$$


Where, $w\left(u_{i}\right)$ is the weight of the first level index, and $w\left(u_{1 i}, u_{2 i}\right)$ is the weight of the second level index. (2)Objective weighting method

In the case of $\mathrm{n}$ different distributed power supply access, $m$ security indexes are normalized, and the entropy of evaluation index is calculated as follows:

$$
\begin{aligned}
& r_{i j}=\frac{1+c_{i j}}{\sum_{i=1}^{m}\left(1+c_{i j}\right)} \\
& E_{j}=\frac{1}{\ln m} \sum_{i=1}^{m} r_{i j} \ln r_{i j}
\end{aligned}
$$

Where, $\mathrm{c}_{i j}$ is the normalized value of each index, $i=1,2, \cdots, m ; j=1,2, \cdots, n$ 。

Furthermore, the entropy weight of the evaluation index is calculated as follows:

$$
w_{2 j}=\frac{1-E_{j}}{n-\sum_{j=1}^{n} E_{j}}
$$

\subsubsection{Weighting calculation of subjective and} objective combination based on chi-square distance

The chi-square distance method is adopted to optimize the combination weighting scheme, calculate the distance between the combination weight and the subjective and objective weight, and find the optimal result, so that it contains more weight information. Chi-square distance is obtained according to chi-square statistics, which measures the difference between data. The smaller the chi-square distance is, the smaller the difference will be, and conversely, the greater the difference will be. Chi-square distance has been applied to many problems to measure data differences and achieved good results.

The combination weight $w_{i}$ can obtain the combination of subjective weight $w_{1 i}$ and objective weight $w_{2 i}$ of the evaluation index. The combined weight is:

$$
w_{i}=\alpha_{1} w_{1 i}+\alpha_{2} w_{2 i}, \alpha_{1}+\alpha_{2}=1
$$

Where, the combined weight of $w_{i}=\left(w_{1}, w_{2}, \cdots, w_{n}\right)$ evaluation index fusion and the single weight based on fuzzy AHP and entropy weight method are $w_{1 i}=\left(w_{11}, w_{12}, \cdots, w_{1 n}\right)$ and $w_{2 j}=\left(w_{21}, w_{22}, \cdots, w_{2 n}\right)$.

The combined weight optimization model based on chi-square distance is as follows:

$$
\left\{\begin{array}{cc}
\min \text { Score }=\min & \left(\sum_{i=1}^{n} \frac{\left(w_{i}-w_{1 i}\right)^{2}}{w_{i}+w_{1 i}}+\sum_{i=1}^{n} \frac{\left(w_{i}-w_{1 i}\right)^{2}}{w_{i}+w_{2 i}}\right) \\
\text { st. } & \alpha_{1}+\alpha_{2}=1 \text { and } \alpha_{1}, \alpha_{2}>0
\end{array}\right.
$$

Solve to get the optimal combination weight $w_{i}=\left(w_{1}, w_{2}, \cdots, w_{n}\right)$.

\subsection{Comprehensive evaluation of safety situation}

According to ER analytic algorithm, the confidence degree of $\mathrm{V}_{\mathrm{j}}$ corresponding to the evaluation level of the security index is obtained:

$$
\beta_{j}=\frac{\prod_{i=1}^{n}\left[w_{i} r_{j, i}+1-w_{i}\right]-\prod_{i=1}^{n}\left[1-w_{i}\right]}{\sum_{j=1}^{N} \prod_{i=1}^{n}\left[w_{i} r_{j, i}+1-w_{i}\right]-N \prod_{i=1}^{n}\left[1-w_{i}\right]}
$$

Where, $w_{i}$ is the fusion weight of evaluation index $x_{i}$, $r_{j, i}$ is the confidence of the value of evaluation index $i$ to grade $V_{j}$, and $\mathrm{n}$ is the number of evaluation indexes, so as to obtain the confidence of the evaluation grade $V_{j}$ corresponding to the safety index.

\section{Analysis of examples}

\subsection{Example system and its parameters}

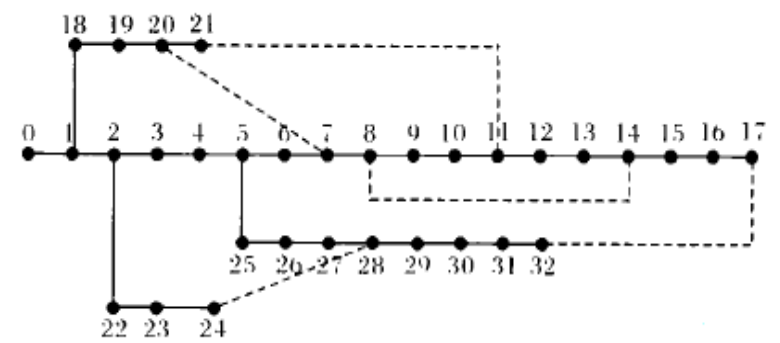

Figure 1 Ieee 33-node distribution network diagram In order to verify the scientificness and rationality of the above safety evaluation system, subjective and objective weight optimization based on chi-square distance, and comprehensive evaluation based on ER algorithm, the topology graph of 33-node distribution network is selected in this paper, as shown in Figure 1. Detailed parameters are included in IEEE TEST FEEDER.

The influence of distributed power access on the safety of distribution network is studied. The security situation of distributed power supply access to distribution network is calculated by the security situation evaluation method of distributed power supply access in this paper.

\subsection{Calculate the weight of each index and optimize it}

Under the conditions of different photovoltaic capacities, different access locations, and different photovoltaic combination modes, active power sustained release, voltage fluctuation, network loss rate, and system equilibrium are considered.

According to the objective weight method in Section 3.3.2, the objective weight set of the distribution network security index determined by the entropy weight method is: 


\begin{tabular}{|c|c|c|c|c|c|c|c|}
\hline \multicolumn{7}{|c|}{ Table 2 Objective weight sets of evaluation indexes } \\
determined by entropy weight method
\end{tabular}

The weight optimization results based on chi-square distance in Section 3.3.2 are shown in Figure 2:

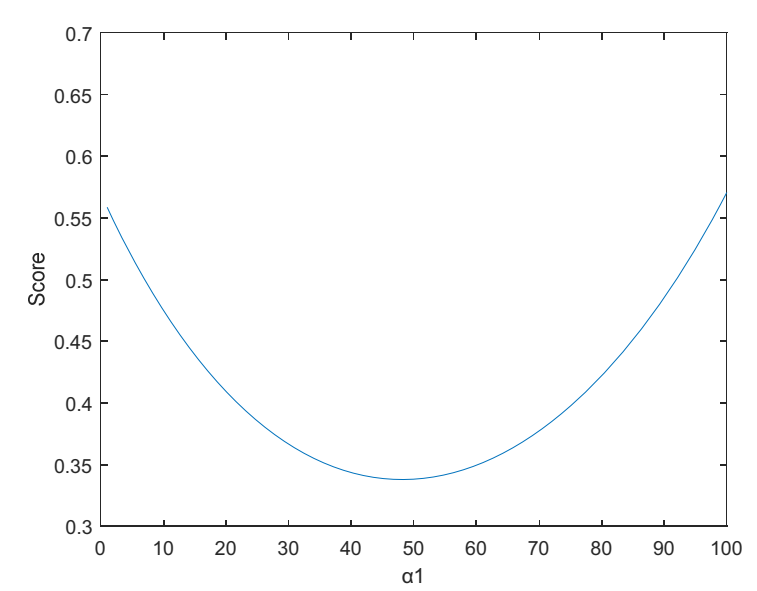

Figure 2 Score of chi-square distance optimization weight

Based on chi-square distance optimization, the combined weight of evaluation index fusion is obtained.

Where $\alpha_{1}=0.48, \alpha_{2}=0.52$ 。

\begin{tabular}{|c|c|c|c|}
\hline \multicolumn{3}{|c|}{ Table 3 Combined weights of safety situation assessment } \\
indexes of distribution network \\
\hline & $\begin{array}{c}\text { Fuzzy } \\
\text { analytic } \\
\text { hierarchy } \\
\text { process }\end{array}$ & $\begin{array}{c}\text { Entropy weigh } \\
\text { t method }\end{array}$ & $\begin{array}{c}\text { Combination wei } \\
\text { ght }\end{array}$ \\
\hline $\mathrm{U}_{11}$ & 0.0750075 & 0.14216230 & 0.109927996 \\
\hline $\mathrm{U}_{12}$ & 0.0897624 & 0.199662685 & 0.146910548 \\
\hline $\mathrm{U}_{13}$ & 0.0541698 & 0.273046214 & 0.167985535 \\
\hline $\mathrm{U}_{14}$ & 0.1920603 & 0.000751515 & 0.092579732 \\
\hline $\mathrm{U}_{21}$ & 0.2846637 & 0.164234070 & 0.222040292 \\
\hline $\mathrm{U}_{22}$ & 0.1781136 & 0.021294536 & 0.096567687 \\
\hline $\mathrm{U}_{23}$ & 0.1262227 & 0.198848676 & 0.163988208 \\
\hline
\end{tabular}

\subsection{The establishment of evaluation level}

The confidence distribution $\mathrm{R}$ of the evaluation index was obtained by considering the sustained release of active power, voltage fluctuation, network loss rate and system equilibrium under different photovoltaic capacities, different access locations, and different photovoltaic combination modes:

$$
R=\left\{\begin{array}{ccccccc}
0.1 & 1 & 0.8830 & 0.9893 & 0.7775 & 0.4250 & 1 \\
0.8 & 0 & 0.0757 & 0.0057 & 0.1912 & 0.3321 & 0 \\
0.1 & 0 & 0.0251 & 0.0035 & 0 & 0.1837 & 0 \\
0 & 0 & 0.0089 & 0.0014 & 0 & 0.0503 & 0 \\
0 & 0 & 0.0075 & 0.0741 & 0.0313 & 0.0093 & 0
\end{array}\right\}
$$

According to the known combination weight and the evaluation grade corresponding to the evaluation index, then the confidence degree of the evaluation grade $V_{i j}$ corresponding to the safety:

\begin{tabular}{|c|c|c|c|c|c|}
\hline \multicolumn{5}{|c|}{ Table 4 Safety situation evaluation of distribution network } \\
\hline$V_{j}$ & $V_{1}$ & $V_{2}$ & $V_{3}$ & $V_{4}$ & $V_{5}$ \\
\hline$\beta_{j}$ & 0.8261 & 0.1438 & 0.0218 & 0.0037 & 0.0047 \\
\hline
\end{tabular}

The above results show that $82.61 \%$ of the experts think the security posture is very good, $14.38 \%$ think the security posture is good, $2.18 \%$ think the security posture is moderate, $0.37 \%$ think the security posture is poor, and only $0.47 \%$ think the security posture is poor. By applying the principle of maximum membership, according to the results of this comprehensive evaluation, it is shown that the security situation level of distribution network with distributed power supply is very good.

\section{Conclusion}

This article puts forward the index system of the safety of the distributed power distribution network access includes access to the location and access capacity, power quality, in many aspects, such as the network loss rate, equilibrium and indicators, and in full consideration of the distributed power supply and load fluctuation and its uncertainty, this paper proposes a distributed power distribution network access to the safety assessment method.

Based on the distribution network security evaluation index on the basis of matter-element matrix and utility theory is used to determine the assessment level, and USES the fuzzy analytic hierarchy process (AHP) and entropy weight method to extract the weight, in view of the traditional single empowerment methods using the method of combination of empowerment and optimized based on chi-square distance, both the index of subjective and objective information, and then make the evaluation results more objective and comprehensive. The evaluation based on ER algorithm provides a new idea for multi-index evaluation method.It accurately reflects the fluctuation of distributed power supply and the influence of uncertainty on the safety of distribution network.It makes the evaluation result more comprehensive, the method is simple and feasible, and has certain use value, and provides the foundation for the security situation evaluation of distributed power supply access to distribution network.

\section{References}

1. Ge, S.Y., Wang,H.M., Wang,Y.S., (2012) Reliability evaluation of distribution system with distributed wind and solar storage.Automation of Electric Power Systems, 05: 21-28.

2. Lin, K.,(2020) Brief Analysis on the Influence of access to distributed Power on distribution Network.Science and Technology and Innovation, 19:84-85.

3. Liu, R.X., Zhang, J.H., Wu, D.,(2011) Research 
on static security evaluation index of distribution network based on risk theory.Power System Protection and Control, 15: 96-102.

4. Gao, Y.H., (2019) Safety monitoring and evaluation for photovoltaic power distribution network monitoring system. Information Technology, 03:67-72.

5. Li, Y.Z., Huang, J., Bai, Q., (2019) Analysis of the influence of distributed power access on distribution network voltage and its reactive power optimization.Electronic Design Engineering, ,27(24):135-139.

6. Zhang, Z.W., Zhao, J.Q., Han, J.B., (2017) Cooperative optimization control of the main distribution network considering the access of a large number of distributed power sources. Power Grid and Clean Energy,07: 114-119+126.

7. Wang, X.Q., Liu, G.Y., Zeng, Y., (2014) Analysis of voltage and reactive power control effect of distribution network with distributed power access.Power System Protection and Control, 1: 47-53.

8. Fan, R.N., Bi R., Han, P.P., (2016) A dynamic assessment method for the security of distribution networks with photovoltaics.Proceedings of the Electrical Engineering Society, 000(004): P.41-46.

9. Raghavendra, P, Gaonkar, D. N., (2016) Online voltage estimation and control for smart distribution networks. Journal of Modern Power Systems and Clean Energy, 4(1): 40-46.

10. Li, Q.L., Dai, S.Y., Ding, T., Chen, H.K., Wang, Y., Zeng, L., (2020) Comprehensive evaluation of power quality and energy consumption of low-voltage distribution network based on subjective and objective combination weighting method.Electrical Measurement and Instrumentation,57(12):52-59.

11. S. H. Karaki,R. B. Chedid,R. Ramadan, (1999) Probabilistic performance assessment of autonomous solar-wind energy conversion systems.IEEE Transactions on Energy Conversion, 14(3):766-772.

12. Chen, F., Wang, W., Xu, L.J., (2012) Analysis of distribution network voltage changes caused by distributed power access.Journal of Electric Power System and Automation, 04:149-153.

13. Huang, X.K., Wang, H., Wang, Y.B., (2014) Principle and strategies of voltage rise regulation for grid-connected photovoltaic generation system at point of common coupling. Automation of Electric Power Systems,38(3): 112-117. 